\title{
MÉTODOS PARA DETERMINAÇÃO DE ATIVIDADE ANTIOXIDANTE IN VITRO EM SUBSTRATOS ORGÂNICOS ${ }^{\#}$
}

\author{
Clayton Q. Alves e Jorge M. David* \\ Instituto de Química, Universidade Federal da Bahia, Campus Ondina, 40170-280 Salvador - BA, Brasil \\ Juceni P. David \\ Faculdade de Farmácia, Universidade Federal da Bahia, Campus Ondina, 40170-280 Salvador - BA, Brasil \\ Marcus V. Bahia \\ Centro de Formação de Professores, Universidade Federal do Recôncavo da Bahia, 45300-000 Amargosa - BA, Brasil \\ Rosane M. Aguiar
}

Departamento de Química e Exatas, Universidade Estadual do Sudoeste da Bahia, R. José Moreira Sobrinho, s/n, 45200-000

Jequié - BA, Brasil

Recebido em 21/6/10; aceito em 17/8/10; publicado na web em 20/10/10

\begin{abstract}
METHODS FOR DETERMINATION OF IN VITRO ANTIOXIDANT ACTIVITY FOR EXTRACTS AND ORGANIC COMPOUNDS. In the literature there are a considerable number of chemical and biochemical tests for evaluation of in vitro antioxidant activities of pure compounds or fractions and organic extracts. These tests are important tools for screening of synthetic and natural bioactive compound as well as they can be employed in food chemistry. This work is a critical review of the main methods employed for in vitro antioxidant determination.
\end{abstract}

Keywords: antioxidant activity; oxygen reactive species; radicalar quenching.

\section{INTRODUÇÃO}

O termo oxidação de uma substância era comumente definido como a incorporação de oxigênio em sua estrutura. Atualmente, pode ser mais precisamente definido como sendo a conversão de uma substância química em um derivado com menor número de elétrons. Oxidação, portanto, é a perda de um ou mais elétrons para outra substância e o procedimento inverso pode ser considerado como redução. ${ }^{1}$

A transferência de elétrons é um dos processos químicos mais fundamentais para a sobrevivência das células. O efeito colateral dessa dependência é a produção de radicais livres e outras espécies reativas de oxigênio (ERO) que podem causar dano oxidativo. Radicais livres são átomos ou moléculas produzidos continuamente durante os processos metabólicos e atuam como mediadores para a transferência de elétrons em várias reações bioquímicas, desempenhando funções relevantes ao metabolismo. ${ }^{2}$ As principais fontes de radicais livres são as organelas citoplasmáticas que metabolizam oxigênio, nitrogênio e cloro, gerando grande quantidade de metabólitos. ${ }^{3}$

Os radicais livres possuem diferentes papéis no organismo e encontram-se envolvidos na produção de energia, fagocitose, regulação do crescimento celular, sinalização intercelular e síntese de substâncias biológicas importantes. Entretanto, seu excesso apresenta efeitos deletérios, tais como danos ao DNA, proteínas e organelas celulares, como mitocôndrias e membranas, provocando alterações na estrutura e funções celulares e, dessa forma, se encontram envolvidos em diversas patologias a exemplo de câncer, envelhecimento precoce, doenças cardiovasculares, degenerativas e neurológicas, choque hemorrágico, catarata, disfunções cognitivas, etc. ${ }^{4}$ Para combater os radicais livres os organismos vivos produzem substâncias que são capazes de regenerar ou prevenir os danos oxidativos, exercendo seu papel como antioxidante. Além destes, substâncias com habilidade de sequestrar radicais livres podem ser obtidas de fontes externas, como alimentos e bebidas. Quando os antioxidantes produzidos pelo

*e-mail: jmdavid@ufba.br

\#Artigo em homenagem ao Prof. Hans Viertler corpo são insuficientes para combater os radicais livres produzidos pelo organismo, este sofre ações degenerativas através do distúrbio conhecido como estresse oxidativo.

Os estudos sobre radicais livres e o desenvolvimento de novos métodos para avaliação de atividade antioxidante (AA) têm aumentado consideravelmente nos últimos anos. As descobertas do efeito deletério dos radicais livres sobre as células e sua relação com certas doenças, agindo como causador ou agravante, impulsionou a busca por novas substâncias capazes de prevenir ou minimizar os danos oxidativos às células vivas.

Os radicais livres atuam de maneira deletéria também sobre plantas e alimentos. A peroxidação lipídica é a principal causa da deterioração dos corpos graxos. Ela é responsável pela modificação do odor e sabor dos alimentos, bem como perda da qualidade nutricional, acarretando depreciação e/ou rejeição por parte dos consumidores. ${ }^{5}$ A decomposição oxidativa pode ser iniciada por processos térmicos, absorção de raios gama ou radiação ionizante, ou por iniciação química envolvendo íons metálicos ou metaloproteínas. ${ }^{6}$ Visando proporcionar ao consumidor alimentos com mais alto grau de qualidade, existem diversas metodologias descritas na literatura para certificação da qualidade dos corpos graxos, além de procedimentos adotados de modo a minimizar os efeitos da oxidação durante o processo de armazenamento. ${ }^{7}$ Além destas medidas, a adição de antioxidantes aos alimentos industrializados tem sido prática corrente (Tabela 1), razão que justifica o atual interesse pela pesquisa de novos compostos antioxidantes. ${ }^{8}$

\section{MÉTODOS PARA DETERMINAÇÃO DA ATIVIDADE ANTIOXIDANTE (AA)}

Existem diversos métodos para avaliar a atividade antioxidante in vitro de substâncias biologicamente ativas, envolvendo desde ensaios químicos com substratos lipídicos a ensaios mais complexos utilizando as mais diversas técnicas instrumentais. ${ }^{9}$

Estes testes têm se tornado ferramentas usuais e extremamente necessárias na seleção inicial de substâncias que possam ser utilizadas como fármacos, auxiliando os pesquisadores na avaliação da atividade 
de substâncias isoladas de produtos naturais, bem como obtidas de fontes sintéticas. Além disso, estes métodos podem auxiliar na escolha das espécies de planta para estudos químicos e farmacológicos, bem como grau de maturação, condições ambientais, etc. e comprovar a pre-

Tabela 1. Estrutura e propriedade dos antioxidantes sintéticos e naturais mais utilizados

Antioxidante

BHT<smiles>CC(C)(C)c1cc(O)cc(C(C)(C)C)c1O</smiles>

TBHQ<smiles>CC(C)(C)c1cc(O)ccc1O</smiles>

$\begin{array}{lcc}\text { Natureza } & \text { Cinética } & \text { Caráter } \\ \text { sintética } & \text { lenta } & \text { lipofílico } \\ \text { intética } & \text { lenta } & \text { lipofílico }\end{array}$

sintética

lenta

lipofílico

Trolox<smiles>Cc1c(C)c2c(c(C)c1O)CCC(C)(C(=O)O)O2</smiles>

galato de $n$-propila<smiles>CCCOC(=O)c1cc(O)c(O)c(O)c1</smiles>

ácido gálico<smiles>O=C(O)c1cc(O)c(O)c(O)c1</smiles>

quercetina<smiles>O=c1c(O)c(-c2ccc(O)c(O)c2)oc2cc(O)cc(O)c12</smiles>

sintética intermediária hidro e lipofílico rápida

rápida

rápida hidro e lipofílico

natural

natural

natural intermediária lipofílico

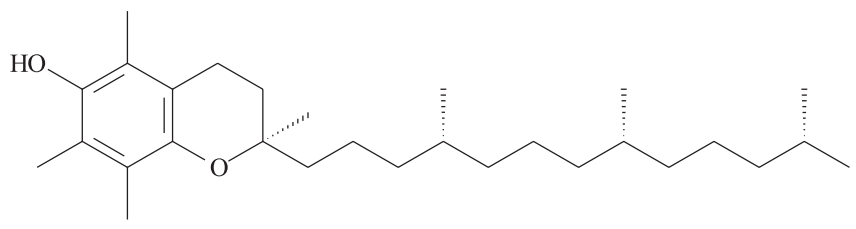


sença de substâncias antioxidantes em alimentos como frutas, legumes e bebidas, ressaltando a importância de uma dieta rica em vegetais.

Devido aos diferentes tipos de radicais livres e as suas diferentes formas de atuação nos organismos vivos, dificilmente existirá um método simples e universal pelo qual a atividade antioxidante possa ser medida precisa e quantitativamente. Assim, a busca por testes mais rápidos e eficientes tem gerado um grande número de métodos para avaliar a atividade de antioxidantes naturais pelo uso de uma grande variedade de sistemas geradores de radicais livres.

Devido à larga divergência dos resultados de testes com antioxidantes naturais em alimentos, muitos protocolos e diretrizes têm sido estabelecidos no sentido de trazer ordem e concordância a este importante campo. ${ }^{10}$ Para se ter uma avaliação mais precisa da AA de uma determinada substância, é necessário saber quais tipos de radicais são gerados, como, onde e a extensão do dano causado. Assim, o entendimento sobre os efeitos dos compostos antioxidantes somente pode ser aperfeiçoado se metodologias mais específicas forem utilizadas, e se estas forem capazes de definir quais produtos são formados e inibidos pelos antioxidantes, e em quais condições, sistemas e alvos de proteção. ${ }^{11}$

Halliwell ${ }^{12}$ propõe algumas questões que devem ser usadas para avaliar a ação antioxidante in vivo, que podem ser respondidas por experimentos simples e seu resultado nos permite rejeitar um possível antioxidante, pois um composto que exibe baixa atividade antioxidante in vitro provavelmente exibirá pouca atividade in vivo.

$\mathrm{O}$ efeito do sequestro de radicais é determinado não somente pela reatividade do antioxidante com o radical, mas também pela sua concentração. Embora muitos antioxidantes reajam rapidamente com o radical hidroxil, muitas moléculas biológicas, que são mais abundantes que os antioxidantes, reagem também rapidamente com esse radical. Por isso é praticamente impossível para algum antioxidante sequestrar o radical hidroxil efetivamente. Outro ponto importante é saber onde os radicais livres são produzidos, e se o antioxidante é capaz de alcançálos. Por exemplo, a vitamina $\mathrm{C}$ é um potente sequestrador para radicais hidrofílicos, mas pobre frente a radicais lipofílicos. ${ }^{13}$

Um dos fatores determinantes para AA de substâncias naturais é a sua solubilidade. Por exemplo, substâncias polares são mais efetivas em grandes quantidades de óleo porque podem se acumular na interface aróleo ou em micelas reversas dentro deste, onde as reações de oxidação lipídica ocorrem com maior frequência devido à alta concentração de oxigênio. Em contraste, antioxidantes não polares são mais efetivos em emulsões porque são retidos nas gotículas de óleo e/ou acumulados na interface óleo-água, onde ocorre a interação entre os hidroperóxidos das gotículas e substâncias pró-oxidantes da fase aquosa como, por exemplo, os metais de transição. ${ }^{14}$ Essa tendência de antioxidantes lipofílicos terem melhor eficiência em alimentos com grande concentração de água, enquanto que antioxidantes polares são mais efetivos em óleo, tem sido denominada como "paradoxo antioxidante". ${ }^{15}$

Os testes antioxidantes em alimentos e sistemas biológicos podem ser classificados em dois grupos: os ensaios usados para avaliar peroxidação lipídica, no qual um lipídio ou substrato lipoproteico sob condições padrão é usado e o grau de inibição da oxidação é medido, e os ensaios usados para medir a habilidade de sequestro de radicais livres. ${ }^{16}$

$\mathrm{Na}$ presente revisão encontra-se uma avaliação crítica dos métodos de determinação de atividade antioxidante in vitro mais utilizados para avaliar a capacidade sequestradora de antioxidantes naturais sobre as ERO.

\section{Sequestro do radical 2,2-difenil-1-picril-hidrazil (DPPH)}

A molécula de DPPH é caracterizada como um radical livre estável em virtude da deslocalização do elétron desemparelhado por toda a molécula. Esta deslocalização confere a esta molécula uma coloração violeta, caracterizada por uma banda de absorção em etanol em cerca de $520 \mathrm{~nm} \cdot{ }^{17}$ Este ensaio se baseia na medida da capacidade antioxidante de uma determinada substância em sequestrar o radical DPPH (Figura 1), reduzindo-o a hidrazina. Quando uma determinada substância que age como doador de átomos de hidrogênio é adicionada a uma solução de DPPH, a hidrazina é obtida com mudança simultânea na coloração de violeta a amarelo pálido.

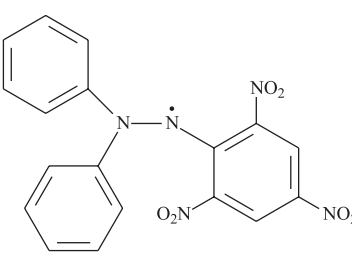

1

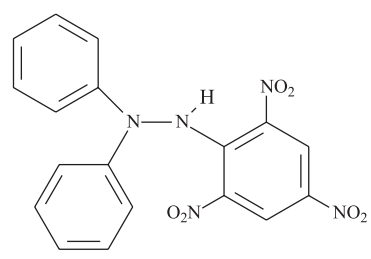

2
Figura 1. Formas radicalar (1) e não radicalar (2) do DPPH

Esta habilidade foi primeiramente avaliada espectroscopicamente por ressonância de elétron spin (RES), uma vez que a intensidade do sinal do radical DPPH é inversamente relacionada com a concentração do antioxidante testado e o tempo de reação. ${ }^{18}$ Entretanto, o método de controle mais utilizado é o decaimento da absorvância no comprimento de onda observado entre 515 a $528 \mathrm{~nm}$, produzido pela adição do antioxidante a uma solução alcoólica do radical DPPH. Este método é considerado, do ponto de vista metodológico, um dos mais fáceis, precisos e reprodutivos na avaliação da atividade antioxidante de sucos de frutas, extratos vegetais e substâncias puras, tais como flavonoides e terpenoides. ${ }^{19}$

Utilizando este método para avaliar a atividade antioxidante de alguns compostos fenólicos, incluindo os ácidos ascórbico e isoascórbico (Figura 2), Brand-Williams et al. ${ }^{20}$ concluíram que a interação de um potencial antioxidante com o DPPH depende, sobretudo, de sua conformação estrutural e do número de grupos hidroxílicos disponíveis. Entretanto, para a maioria das substâncias testadas o mecanismo parece ser muito mais complexo, necessitando de um estudo posterior mais aprofundado.

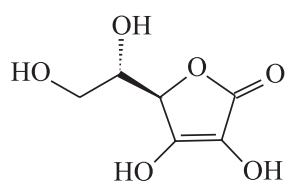

3

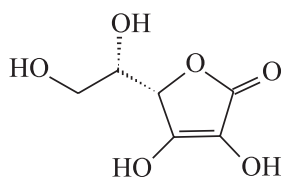

4
Figura 2. Estrutura dos ácidos ascórbico (3) e isoascórbico (4)

Sánchez-Moreno et al. ${ }^{21}$ propuseram uma metodologia para a avaliação da atividade antioxidante levando em conta não somente a concentração do antioxidante, mas também o tempo de reação necessário pra sequestrar este radical, introduzindo assim a eficiência antirradicalar como um novo parâmetro. Utilizando esta metodologia, as AAs de vinhos tinto, rosé e branco foram avaliadas, concluindo que existe uma correlação entre eficiência antirradicalar e concentração de polifenóis presentes nos vinhos. ${ }^{22}$ Embora este seja um teste largamente utilizado, tanto pela simplicidade e rapidez quanto pela reprodutibilidade, os resultados devem ser cuidadosamente interpretados. As substâncias analisadas podem interferir nos resultados caso seus espectros se sobreponham ao do DPPH ao redor de $515 \mathrm{~nm}$ como, por exemplo, os carotenoides. Sendo a acessibilidade estérica o fator determinante da reação, moléculas pequenas que têm melhor acesso ao sítio do radical podem apresentar uma maior atividade aparente quando comparada às moléculas maiores. ${ }^{23}$ 


\section{Método da co-oxidação do $\beta$-caroteno/ácido linoleico}

O $\beta$-caroteno é o mais abundante dos carotenoides e largamente utilizado em terapias. É quase completamente insolúvel em água, mas facilmente solúvel em ambientes hidrofóbicos e solventes pouco polares. Tem sido reportado nos últimos 30 anos que o $\beta$-caroteno exibe alta reatividade com eletrófilos e oxidantes. Muitos estudos têm demonstrado que ele inibe a auto-oxidação de lipídios em tecidos biológicos e produtos alimentícios, porém poucos detalhes da cinética e mecanismo destas reações têm sido revelados. ${ }^{24}$

Diversas técnicas têm sido utilizadas para determinar a atividade antioxidante in vitro, de forma a permitir uma rápida seleção de substâncias e/ou misturas potencialmente interessantes na prevenção de doenças crônico-degenerativas. Dentre estes métodos destaca-se o sistema de co-oxidação do $\beta$-caroteno/ácido linoleico (Figura 3), originalmente descrito por Marco ${ }^{25}$ e modificado por Miller. ${ }^{26}$ Este método nos permite avaliar a capacidade de uma determinada substância prevenir a oxidação do $\beta$-caroteno, protegendo-o dos radicais livres gerados durante a peroxidação do ácido linoleico. A reação pode ser monitorada espectrofotometricamente pela perda da coloração do $\beta$-caroteno em $470 \mathrm{~nm}$, com leitura imediata e em intervalos de 15 min, por um tempo total de 2 h. ${ }^{27}$

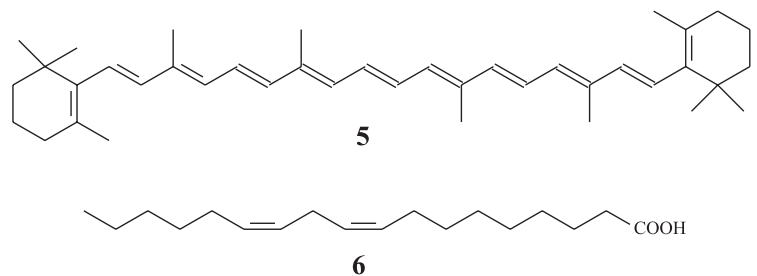

Figura 3. Estrutura do $\beta$-caroteno (5) e do ácido linoleico (6)

O Tween-40 é utilizado como emulsificante e ajuda a dissolver completamente a mistura $\beta$-caroteno/ácido linoleico em clorofórmio que, após total remoção do solvente, é dissolvida em água previamente saturada com oxigênio atmosférico. $\mathrm{O}$ resultado pode ser comparado com padrões sintéticos, como BHA, BHT e trolox, ou naturais, como ácido gálico ou quercetina (Tabela 1).

Este método tem sido amplamente utilizado para avaliar a atividade antioxidante tanto de substâncias isoladas de extratos vegetais, quanto de frutas e bebidas. Dentre várias classes de substâncias naturais ativas, as pro-antocianinas isoladas de extratos de espécies de Leguminosae mostraram ser tão eficientes quanto os antioxidantes comerciais, tais como galato de $n$-propila e $\alpha$-tocoferol (Tabela 1), ${ }^{28}$ enquanto Bandyopadhyay et al. ${ }^{29}$ as utilizaram para testar a AA de extratos de beterraba, gengibre e hortelã, sendo que o gengibre apresentou atividade comparável à dos antioxidantes sintéticos BHA e BHT. Avaliando a AA dos extratos do subproduto do pseudofruto do caju, os quais exibiram expressiva atividade comparada ao BHT, Broinizi et al. ${ }^{27}$ apresentaram perspectivas de se ter um melhor aproveitamento dos resíduos resultantes do processamento industrial do pedúnculo do caju. Hassimotto et al..$^{30}$ avaliaram frutas, vegetais e polpas de frutas consumidas na dieta brasileira, onde as amostras que possuíam maior concentração de antocianinas apresentaram maior AA. Esta metodologia foi ainda adotada para avaliar a AA de compostos presentes em bebidas como chás, café e vinhos, evidenciando a ação benéfica destas bebidas para o consumo humano. ${ }^{31}$

Duarte-Almeida ${ }^{32}$ utilizou leitor de microplacas automáticas e sequenciais, ocasionando maior precisão no método além de evitar o uso de um número grande de cubetas para as replicatas. Desta forma, a adaptação da metodologia para realização em microplacas com leituras automatizadas pode ser uma ferramenta vantajosa.
O método da co-oxidação empregando o sistema $\beta$-caroteno/ácido linoleico é um teste simples e sensível, e por não utilizar altas temperaturas permite a determinação da AA de substâncias termossensíveis, porém apresenta alguns inconvenientes. A utilização do meio emulsionado, por exemplo, interfere nos valores de absorvância causando baixa reprodutibilidade, e a interação do $\beta$-caroteno com o oxigênio proveniente do meio dificulta a interpretação dos resultados. ${ }^{33}$

\section{Análise por fluorescência - ensaio fluorimétrico}

Pesquisas clínicas, farmacêuticas e bioquímicas estão sendo continuamente estimuladas na procura por métodos analíticos mais sensíveis usando microamostras. Espectroscopia por fluorescência é uma das técnicas que combina alta sensibilidade sem perda de especificidade ou precisão. Mais recentemente, o uso de químio e bioluminescência tem aberto novos caminhos na pesquisa e aplicação, primeiramente no campo de imunoensaios. A vantagem no uso de técnicas de bioluminescência é a combinação de uma instrumentação relativamente simples e excelente sensibilidade. ${ }^{34}$ Por apresentar uma série de vantagens, a espectroscopia por fluorescência tem sido largamente utilizada na busca por antioxidantes de fontes naturais, originando assim uma série de métodos que podem auxiliar na seleção e avaliação de substâncias bioativas. ${ }^{35}$

\section{Sequestro do peróxido de hidrogênio $\left(\mathrm{H}_{2} \mathrm{O}_{2}\right)$}

Embora o peróxido de hidrogênio não seja considerado um radical livre, está envolvido de forma direta ou indireta em diversas patologias. Em termos químicos, $\mathrm{H}_{2} \mathrm{O}_{2}$ é fracamente reativo, no entanto exerce papel importante no estresse oxidativo por ser capaz de transpor as membranas celulares facilmente e gerar o radical hidroxil $(\bullet \mathrm{OH}){ }^{36}$

$\mathrm{O}$ peróxido de hidrogênio $\left(\mathrm{H}_{2} \mathrm{O}_{2}\right)$ é gerado in vivo pela dismutação do radical ânion superóxido $\left(\mathrm{O}_{2} \bullet-\right)$ ou é produzido por enzimas oxidases e pela oxidação de ácidos graxos. $\mathrm{H}_{2} \mathrm{O}_{2}$ pode atuar como agente oxidante ou redutor leve, mas não oxida a maioria das moléculas orgânicas facilmente, incluindo lipídios, DNA e proteínas (com exceção de proteínas que apresentem resíduos de metionina ou grupos tiol muito reativos, a exemplo da glutationa (GSH)). O efeito deletério do $\mathrm{H}_{2} \mathrm{O}_{2}$ vem de sua fácil conversão para um radical hidroxil, por exposição à luz ultravioleta (Equação 1) ou por interação com metais de transição como o ferro, através da reação conhecida como reação de Fenton (Equação 2). ${ }^{37}$

$$
\mathrm{H}_{2} \mathrm{O}_{2} \stackrel{\mathrm{uv}}{\longrightarrow} 2 \cdot \mathrm{OH}
$$

Equação 1. Conversão do peróxido de hidrogênio em radical hidroxil

$$
\mathrm{Fe}^{2+}+\mathrm{H}_{2} \mathrm{O}_{2} \longrightarrow \mathrm{Fe}^{3+}+\cdot \mathrm{OH}+{ }^{-} \mathrm{OH}
$$

Equação 2. Reação de Fenton

Diversas técnicas têm sido aplicadas para diferentes tipos de amostras, a mais comum avalia a capacidade de uma substância sequestrar o peróxido de hidrogênio empregando peroxidase da raiz forte (HRP) que utiliza o $\mathrm{H}_{2} \mathrm{O}_{2}$ para oxidar a escopoletina (Figura 4), uma cumarina conhecida por apresentar alta fluorescência, em um produto não fluorescente. Na presença de um antioxidante, a oxidação da escopoletina é inibida e $\mathrm{o}_{2} \mathrm{H}_{2}$ pode ser monitorado por um espectrofluorímetro em $430 \mathrm{~nm} .{ }^{38}$

Szatrowski e Nathan ${ }^{39}$ utilizaram este método para avaliar a concentração de $\mathrm{H}_{2} \mathrm{O}_{2}$ em células tumorais humanas, constatando que estas células produzem grande quantidade deste composto. Gomes et $a l . .^{40}$ avaliaram a capacidade antioxidante dos extratos vegetais de 
<smiles>COc1cc2ccc(=O)oc2cc1O</smiles>

Figura 4. Estrutura da escopoletina

Polypodium leucotomos que, embora tenha apresentado alta atividade antioxidante sobre os radicais hidroxil, ânion superóxido e oxigênio singlete, apresentou baixa atividade contra o peróxido de hidrogênio.

Halliwell ${ }^{12}$ propõe dois pontos que devem ser considerados ao usar este método: há necessidade de checar se a substância teste não funciona como um substrato para a peroxidase, o que poderia decrescer a fluorescência através da competição com a escopoletina; o radical superóxido pode inibir a peroxidase e comprometer a medida de $\mathrm{H}_{2} \mathrm{O}_{2}$ em sistemas geradores de $\mathrm{O}_{2} \bullet$ -

\section{Sequestro do radical peroxil - Método ORAC}

O radical peroxil é um oxidante comumente encontrado em substratos biológicos. É menos reativo que o $\bullet \mathrm{OH}$ possuindo um tempo de meia-vida de segundos a nanossegundos. ${ }^{11}$ Oxygen radical absorbance capacity (ORAC) é um método que se baseia na propriedade fluorescente das proteínas B-ficoeritrina (B-PE) e R-ficoeritrina (R$\mathrm{PE}$ ). Estas proteínas são usadas como indicador fluorescente e foram primeiramente isoladas de Porphyridium cruentum e algas vermelhas, respectivamente. Neste ensaio o radical peroxil, gerado pelar reação do AAPH [dicloreto de 2,2'-azobis(2-amidinopropano)] com oxigênio atmosférico, reage com o indicador fluorescente para formar um produto não fluorescente, que pode ser medido por espectrofotometria com máxima emissão de fluorescência em 575 nm (B-PE) e 578 nm (R-PE).$^{41}$ Este ensaio avalia a atividade antioxidante através da inibição da oxidação, induzida pelo radical peroxil, por transferência de átomos de hidrogênio. A atividade antioxidante de uma dada substância é determinada através da diferença entre a área da amostra subtraída pela área do branco (Net AUC), medida pelo decaimento da fluorescência com a adição da substância antioxidante no decorrer do tempo.

Usando-se Trolox de concentrações conhecidas, uma curva padrão é gerada e a atividade ORAC da amostra é calculada. Este ensaio expressa o resultado em unidade de ORAC ou equivalentes de Trolox, o qual corresponde à quantidade de Trolox em micromols que tem a mesma atividade antioxidante de um litro da solução testada. ${ }^{42}$

Atanasiu et $a l .{ }^{43}$ utilizaram este método para avaliar a atividade antioxidante da caeruloplasmina, uma proteína plasmática envolvida no transporte de cobre, que se mostrou duas vezes mais eficiente que o Trolox. Cao et al.${ }^{44}$ avaliaram a atividade antioxidante e pró-oxidante de alguns flavonoides e observaram que flavonas e flavanonas com um único grupo $\mathrm{OH}$ substituinte nas posições 3, 6, 2' ou 4' e 7, 2', 3' ou 4', respectivamente, exibiram pouca atividade. Flavona com um único $\mathrm{OH}$ substituinte na posição 5 não apresentou atividade detectável, entretanto flavanona com $\mathrm{OH}$ substituinte na posição 6 apresentou atividade maior que a do Trolox. Entre os compostos com a mesma estrutura, diferindo apenas no número de hidroxilas, a atividade antioxidante foi proporcional ao número de substituintes $\mathrm{OH}$ na estrutura da molécula. Assim, os compostos camferol, quercetina e miricetina (Figura 5) exibiram 2,7; 3,3 e 4,3 equivalentes de Trolox, respectivamente, comprovando a importância de grupos hidroxílicos substituintes em C-3'e C-4' na atividade sequestradora de radicais peroxil.

Alguns flavonoides exibiram forte atividade antioxidante sobre radicais livres, porém demonstraram atividade pró-oxidante em presença de metais de transição. A atividade antioxidante ou pró-oxidante dos flavonoides depende de sua estrutura, da concentração e da fonte de radicais livres. Em geral, quanto maior o número de substituintes $\mathrm{OH}$, maior a atividade. ${ }^{37}$<smiles>O=c1cc(-c2ccccc2)oc2ccccc12</smiles>

Flavona<smiles>[R]c1cc(-c2oc3cc(O)cc(O)c3c(=O)c2O)cc([R])c1O</smiles>

Figura 5. Estrutura de alguns flavonoides

O uso de B-ficoeritrina tem diminuído devido a sua variabilidade na reatividade, por ser fotossensível, apresenta descoloração ao ser exposta à luz de excitação, e por sua alta afinidade por polifenóis, particularmente proantocianidinas, o que tem levado a resultados inconsistentes ${ }^{45}$ Os indicadores fluorescentes preferidos atualmente são fluoresceína e diclorofluoresceina (Figura 6), que são mais estáveis e menos reativos. ${ }^{23}$<smiles>O=C(O)c1ccccc1-c1c2ccc(=O)cc-2oc2cc(O)ccc12</smiles>

7<smiles>O=C(O)c1ccccc1-c1c2cc(Cl)c(=O)cc-2oc2cc(O)c(Cl)cc12</smiles>

8
Figura 6. Estrutura da fluoresceína (7) e diclorofluoresceína (8)

\section{Sequestro de radical superóxido - xantina oxidase}

A produção do ânion superóxido $\left(\mathrm{O}_{2} \bullet-\right)$, uma espécie reativa de oxigênio, é essencial para a defesa de organismos vivos e atua na transferência de sinais entre células vivas. Entretanto, a superprodução de $\mathrm{O}_{2} \bullet$ - causa estresse oxidativo e está envolvida em diversas patologias. $^{46}$

Xantina oxidase (XO) é a enzima responsável pela transformação tanto da hipoxantina em xantina, quanto desta em ácido úrico, tendo como consequência a produção de peróxido de hidrogênio e radical superóxido (Figura 7), por isso é considerada uma das principais fontes biológicas de espécies reativas de oxigênio. ${ }^{47}$ Assim, é possível que a inibição deste processo enzimático por compostos que exibem propriedades antioxidante ou inibitória da xantina oxidase possam ter uso terapêutico. ${ }^{48}$

A atividade de um grande número de substâncias pode ser medida em termos da atividade sequestradora do radical superóxido ou através da inibição da ação da xantina oxidase. $\mathrm{O}_{2} \mathrm{O}_{2}-$ pode ser gerado por distintos sistemas enzimáticos, entre eles a reação catalisada pela enzima xantina oxidase, ou pelo sistema não enzimático através da reação de metassulfato de fenazina (PMS) com NADH e oxigênio molecular. ${ }^{49}$

No método utilizado para avaliar a capacidade sequestradora, o radical $\mathrm{O}_{2} \bullet$ - produzido reduz nitroblue tetrazolium (NBT) a formazan em pH 7,4 e temperatura ambiente (Figura 8), e a geração do formazan é acompanhada por espectrofotometria pela mudança da coloração amarelo pálido do NBT para uma coloração púrpura do formazan em 


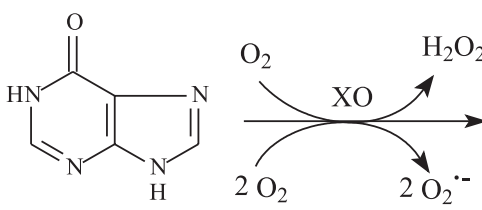

Hipoxantina<smiles>O=c1[nH]c(=O)c2nc[nH]c2[nH]1</smiles>

Xantina

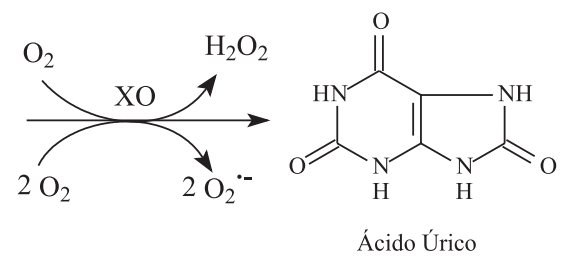

Figura 7. Conversão de hipoxantina a xantina e desta a ácido úrico

$560 \mathrm{~nm}$. As moléculas que atuam como antioxidante reagem com $\mathrm{O}_{2}^{\bullet-}$ inibindo a produção do formazan. ${ }^{50}$ Gaulejac et al. ${ }^{51}$ utilizaram este método para avaliar a atividade sequestradora do radical superóxido em vinho tinto, e concluíram que esta atividade, usualmente atribuída aos taninos procianídicos, está também relacionada às antocianinas presentes nesta bebida.<smiles>O=c1[nH]c(=O)c2nc[nH]c2[nH]1</smiles>

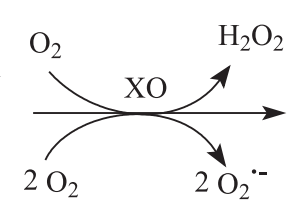<smiles>O=c1[nH]c(=O)c2[nH]c(=O)[nH]c2[nH]1</smiles>

Xantina

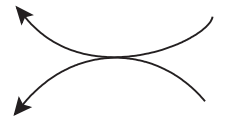<smiles>[R]NN=C([R])N=[V]</smiles><smiles>[R]c1nn([R])[n+]([R])n1</smiles>

Ácido Úrico

NBT

Figura 8. Formação do formazan a partir do NBT

Algumas modificações no método são encontradas na literatura como, por exemplo, o uso de cloreto de hidroxilamônio como agente oxidante ao invés do NBT. A consequente produção de nitrila é acompanhada espectrofotometricamente em $530 \mathrm{~nm}$ e a atividade antioxidante é medida pela inibição desta produção. ${ }^{52}$

No método utilizado para avaliar a capacidade de inibição da atividade da XO no sistema xantina/xantina oxidase, a atividade é medida pela avaliação da produção do ácido úrico, que é formado juntamente com o radical superóxido, por espectrofotometria em $290 \mathrm{~nm} \cdot{ }^{53}$ Cos et $a l .{ }^{54}$ utilizaram esta metodologia para avaliar a atividade inibitória de flavonoides sobre a XO, concluindo que flavanonas, di-hidroflavonóis e flavanóis não são capazes de inibir a ação da enzima. No entanto, entre as flavonas e flavonóis a presença de grupos hidroxilas nas posições C-5 e C-7 aumenta a ação inibitória, enquanto a presença destes grupos ligados em C-6 e C-3 diminui consideravelmente este efeito. A substituição de grupos hidroxila por açúcares diminui a ação sobre a enzima XO em relação às suas respectivas agliconas, indicando que as interações estéricas reduzem o efeito inibidor de flavonoides sobre a xantina oxidase. Um dos fatores determinantes na ação inibitória é a planaridade destas moléculas. Com a presença da dupla ligação entre C-2 e C-3, o anel B estará acoplado com os anéis A e C através da conjugação. A saturação desta dupla ligação destruirá a conjugação e a coplanaridade da molécula e, consequentemente, sua ação sobre a enzima. Os resultados obtidos estão em acordo com os dados descritos na literatura, os quais destacam como características importantes para AA de flavonoides a dupla ligação entre C-2 e C-3, o número de hidroxila presentes nos anéis A, B e C e a presença de uma carbonila em C-4. ${ }^{37,55}$

Ramallo et al. ${ }^{56}$ adaptaram este método aplicando uma solução contendo a enzima xantina oxidase e NBT sobre a superfície de placa cromatográfica previamente eluída com as amostras teste em solvente

apropriado. Após secagem, a placa é imersa em uma solução contendo o substrato xantina, para iniciar a reação. A oxidação da xantina produz radicais superóxido, os quais reduzem o NBT (de coloração amarelo pálido) a formazan, que apresenta coloração púrpura. Substâncias capazes de inibir a ação da enzima irão impedir a produção do radical superóxido e, consequentemente, a produção do formazan. A ação inibitória da XO é, então, detectada como manchas brancas sob a superfície púrpura da placa, que é comparada com substância padrão, previamente eluída junto com as amostras, em quantidades decrescentes de concentração até o limite de detecção de 5 ng.

\section{Sequestro do radical hidroxil - método 2: deoxirribose}

$\mathrm{O}$ radical hidroxil $(\mathrm{HO} \bullet)$ é um dos mais deletérios radicais livres, pois sua meia-vida é muito curta e dificilmente pode ser sequestrado in vivo. Em experimentos in vitro pode ser sequestrado facilmente devido a sua alta reatividade, porém para que esse resultado se reproduza in vivo é necessário que sejam ministradas altas concentrações de antioxidante. Este radical frequentemente ataca as moléculas por abstração de hidrogênio e pode ser gerado através da reação do $\mathrm{H}_{2} \mathrm{O}_{2}$ com metais de transição ou pela homólise da água por exposição à radiação ionizante. ${ }^{4,57}$

Um dos métodos específicos para determinar o sequestro do radical hidroxil é o ensaio empregando-se a 2-deoxirribose. Neste ensaio, $\bullet \mathrm{OH}$ é gerado pela reação do cloreto férrico $\left(\mathrm{FeCl}_{3}\right)$ e ácido etilenodiaminotetracético (EDTA) na presença de ascorbato, que reage para formar Ferro(II)-EDTA juntamente com ascorbato oxidado. O $\mathrm{H}_{2} \mathrm{O}_{2}$ reage com Ferro(II)-EDTA para formar Ferro(III)-EDTA e $\bullet O H$ através da reação de Fenton. O radical formado pode então reagir com 2-deoxirribose para formar produtos que, sob aquecimento com ácido tiobarbitúrico (ATB) em pH baixo, apresentam coloração rosada, sendo monitorado por espectrofotometria na região do visível $(532 \mathrm{~nm}) .^{58}$ Substâncias que tenham propriedades antioxidantes podem competir com a 2-deoxirribose pelo radical, produzindo uma diminuição na intensidade da coloração. ${ }^{59}$ Aruoma et al. ${ }^{60}$ utilizaram este método para avaliar a atividade antioxidante e pró-oxidante do ácido gálico e seus derivados, concluindo que estas substâncias apresentam ação antioxidante sobre ERO's, porém apresentam efeito pró-oxidante quando em presença de metais de transição como $\mathrm{Fe}^{+3}$. Este método também foi utilizado por Martínez-Tomé et al. ${ }^{61}$ na avaliação da atividade antioxidante de aminoácidos extraídos de brócolis de algumas espécies mediterrâneas, dos quais a glutamina apresentou mais alta atividade sequestradora do radical hidroxil quando comparado com antioxidantes comerciais.

Este teste é considerado um método simples e barato de medir a reatividade de algumas moléculas orgânicas (ex. ADP e ATP) frente ao radical $\bullet \mathrm{OH}$, porém algumas precauções devem ser observadas para se obter resultados satisfatórios: o antioxidante testado não deve reagir com o precursor do radical hidroxil $\left(\right.$ ex. $\left.\mathrm{H}_{2} \mathrm{O}_{2}\right)$, caso contrário não haverá formação do mesmo; a reação do antioxidante com $\mathrm{o} \bullet \mathrm{OH}$ não deve gerar produtos que apresentem coloração. ${ }^{12}$

Hagerman et al ${ }^{62}$ propuseram uma modificação do método, onde se omite a utilização de ascorbato permitindo avaliar o potencial de algumas substâncias se comportarem como pró-oxidantes. Substâncias que apresentem ação pró-oxidante podem reduzir o $\mathrm{Fe}^{+3} \mathrm{a} \mathrm{Fe}^{+2} \mathrm{e}$, 
assim, permitem a reação de Fenton, a qual culminará na produção do radical hidroxil e, consequentemente, degradação da 2-deoxirribose.

Para identificar substâncias com propriedades quelantes, outra modificação do ensaio é realizada sem a presença do EDTA, onde alguns compostos podem inibir a formação da coloração não por reagirem com o radical hidroxil, mas por quelarem o íon ferro e impedirem a formação de $\bullet \mathrm{OH}^{63}$

Variação do método de degradação da 2-deoxirribose: inibição da peroxidação lipídica empregando-se homogenato de cérebro de ratos

Alguns autores utilizam o ácido tiobarbitúrico para avaliar a atividade antioxidante de substâncias frente ao radical peroxil, empregando homogenato de cérebro de ratos.

O cérebro é particularmente vulnerável à peroxidação lipídica, pois consome uma grande quantidade de oxigênio e é rico em ácidos graxos poli-insaturados altamente peroxidáveis; além disso, sua capacidade antioxidante é limitada. ${ }^{64} \mathrm{Em}$ cérebros sob estresse oxidativo, o ferro pode ser liberado de proteínas de armazenamento, como ferritina ou heme proteínas, e contribuir para a iniciação e propagação da peroxidação lipídica. Acredita-se que o radical hidroxil esteja envolvido na iniciação da peroxidação lipídica. Entretanto, alguns investigadores têm questionado essa afirmação, sugerindo que $\mathrm{Fe}^{+2} \mathrm{e}$ $\mathrm{Fe}^{+3}$ podem estar envolvidos em um complexo ferro-oxigênio, agindo como espécie oxidante. ${ }^{65}$ Este ensaio é similar ao que utiliza 2-deoxirribose, no entanto o radical $\bullet \mathrm{OH}$ produzido pela adição de $\mathrm{Fe}^{+2}$, ácido ascórbico e $\mathrm{H}_{2} \mathrm{O}_{2}$ causa peroxidação no homogenato de cérebro de ratos. O produto da peroxidação lipídica reage com o ATB para formar substâncias que apresentam coloração rosada sob aquecimento, sendo acompanhada por espectrofotometria em $532 \mathrm{~nm}$. A oxidação é inibida com a adição de um antioxidante, sendo acompanhada pela redução na absorvância. ${ }^{66} \mathrm{~A}$ formação da coloração é resultado de um complexo formado pelos produtos oxidados dos ácidos graxos insaturados com o ATB. Um dos maiores produtos formados desta degradação é o malondialdeído (MDA), embora outros produtos de oxidação, incluindo aldeídos $\alpha, \beta$ insaturados e vários precursores não voláteis destas substâncias possam também estar envolvidos. ${ }^{67}$ Embora este teste seja largamente utilizado, não é específico, e as condições reacionais têm um efeito significativo no desenvolvimento da coloração. Uma das vantagens no uso do homogenato de cérebro de ratos é o emprego de moléculas alvo provenientes de tecido animal na busca por substâncias antioxidantes.

Oboh e Helen ${ }^{64}$ utilizaram este método para avaliar a AA do extrato aquoso das folhas de Salvia officinalis, o qual apresentou alta habilidade em proteger o homogentato de cérebro e fígado de ratos da peroxidação lipídica. Esta habilidade pode ser atribuída à alta AA da vitamina $\mathrm{C}$ e de compostos fenólicos presentes nas folhas deste vegetal.

\section{Sequestro do ácido hipocloroso}

$\mathrm{O} \mathrm{HOCl}$ é um potente agente oxidante gerado nos neutrófilos pela reação de íons cloreto $\left(\mathrm{Cl}^{-}\right)$com peróxido de hidrogênio catalisado pela mieloperoxidase (MPO). Acredita-se que a produção de $\mathrm{HOCl}$ por este sistema constitui um importante mecanismo de defesa contra micro-organismos, entretanto, sua produção excessiva pode levar a danos nos tecidos, contribuindo para o desenvolvimento de doenças como aterosclerose e câncer. ${ }^{68}$

$\alpha_{1}$-Antiproteinase $\left(\alpha_{1}\right.$-AP) é um potente inibidor da serina protease em fluidos do corpo humano, mas é também muito sensível ao ataque por $\mathrm{HOCl}$. Por exemplo, $\alpha_{1}$-AP inibe a enzima elastase. Quando $\alpha_{1}$-AP é inativada pelo ácido hipocloroso, perde a capacidade de inibir a elastase. Assim, a habilidade de um composto em proteger $\alpha_{1}$-AP tem sido adotada como método para avaliar a atividade antioxidade de substâncias em relação ao $\mathrm{HOCl}$, sendo monitorada por espectrofotometria $(410 \mathrm{~nm})$. Wasil et al.${ }^{69}$ avaliaram a atividade antioxidante de fluidos humanos extracelulares através da produção de $\mathrm{HOCl}$ usando $\mathrm{MPO} / \mathrm{H}_{2} \mathrm{O}_{2} / \mathrm{Cl}^{-}$(Equação 3) como fonte desta substância e concluíram que esta atividade se deve, em grande parte, à albumina presente nestes fluidos. A ação inibitória da $\alpha_{1}$-AP sobre a elastase (extraída do pâncreas de porco), após a adição do substrato elastase [N-(3-carboxipropionil)trialanil p-nitroanilida], foi monitorada espectrofotometricamente pelo aumento linear da absorbância em $410 \mathrm{~nm}$.

$$
\mathrm{H}_{2} \mathrm{O}_{2}+\mathrm{Cl}^{-}+\mathrm{H}^{+} \stackrel{\mathrm{MPO}}{\longrightarrow} \mathrm{H}_{2} \mathrm{O}+\mathrm{HOCl}
$$

Equação 3. Geração do ácido hipocloroso

Aruoma et al. ${ }^{60}$ utilizaram uma modificação deste método para avaliar a atividade antioxidante do ácido gálico e seus derivados, no qual $\mathrm{HOCl}$ é gerado imediatamente antes do uso através da reação do hipoclorito de sódio em pH 6,2 com ácido sulfúrico diluído. Seguindo esta metodologia, Martínez-Tomé et al. ${ }^{57}$ avaliaram a AA de aminoácidos extraídos de brócolis, no qual a asparagina mostrou mais alta atividade sequestradora do ácido hipocloroso.

\section{TÉCNICAS ELETROQUÍMICAS}

Com substâncias puras é possível realizar não somente uma caracterização eletroquímica, como também obter correlações entre aspectos estruturais e mecanismo de atividade antioxidante. ${ }^{70}$ Assim, é possível utilizar técnicas eletroanalíticas para determinar a atividade antioxidante de substâncias de ampla distribuição em vegetais tais como ácidos ascórbico e elágico, resveratrol, flavonoides, hesperidina, taninos, antocianinas e derivados dos ácidos benzoico e cinâmico. ${ }^{71}$ Alguns aspectos podem ser determinados no que diz respeito aos mecanismos de oxidorredução. Entre eles pode-se destacar: avaliação do efeito de substituintes e conjugação de duplas no deslocamento de potenciais redox; efeito da participação do próton ou dependência do $\mathrm{pH} ;{ }^{72}$ efeito de solvente e, número de elétrons ou etapas envolvidas. ${ }^{70,73}$

As técnicas voltamétricas podem correlacionar potenciais de oxidação, intensidade de corrente e/ou outros parâmetros eletroquímicos com a capacidade antioxidante, portanto podem se mostrar mais seletivas e sensíveis que os demais métodos espectrométricos. Entre as técnicas mais difundidas destacam-se a voltametria cíclica (VC) e a voltametria de pulso diferencial (VPD). As informações mais importantes fornecidas pela voltametria cíclica são Ip, $a, I p, c$, Ep, a e Ep,c, respectivamente, correntes de picos anódico e catódico e potenciais de picos anódico (relativo ao processo de oxidação) e catódico (relativo ao processo de redução), respectivamente. ${ }^{72,74}$ Quanto maior o valor de Ep,a, menor é o poder doador de elétron da espécie em estudo e, portanto, teoricamente, menor seu poder antioxidante.

As técnicas coulométricas baseiam-se na medida da quantidade de eletricidade ou carga requerida para oxidar ou reduzir um analito alvo. Baseiam-se no princípio da proporcionalidade entre número de elétrons (n) que fluem pelo eletrodo e quantidade em moles de substância eletroativa envolvida na reação eletroquímica $\left(1^{\mathrm{a}}\right.$ Lei de Faraday); logo, um requisito importante é que a reação eletrolítica se dê com máxima eficiência.

Através do uso da eletrólise em fluxo contínuo, observaram-se boas correlações entre intensidade de corrente (I) e atividade antioxidante de diversas espécies eletroativas naturais, tais como catequinas e outros polifenóis. Ademais, a aplicação destas técnicas a compostos polifenólicos permite ainda relacionar os valores de $\mathrm{n}$ (número de elétrons) ou de I (corrente) aos números de hidroxilas. Os resultados obtidos para a atividade antioxidante de 34 produtos naturais através 
de técnicas diversas demonstraram que a correlação entre métodos eletroquímicos e capacidade de sequestrar radicais, i.e. ensaio DPPH, é maior quando comparada ao número de elétrons (eletrólise em fluxo contínuo) e ao potencial de oxidação (voltametria cíclica). ${ }^{73}$

Além das anteriores, várias outras técnicas baseadas em métodos eletroquímicos vêm sendo implementadas. Dentre estas, se destacam os métodos baseados na proteção à oxidação de bases de DNA e aqueles baseados na capacidade de redução do $\mathrm{Fe}^{3+} \mathrm{e} \mathrm{Ce}^{4+}$.

Um procedimento simples para a detecção voltamétrica da atividade antioxidante de extratos de plantas ou de substâncias puras é aquele baseado na proteção contra danos no DNA. Neste método, um eletrodo cuja superfície foi previamente modificada com DNA é submetido à voltametria cíclica, em diferentes soluções contendo os extratos vegetais ou fitoantioxidantes, cuja atividade antioxidante se pretende determinar. Em princípio, os ensaios efetuados em soluções eletrolíticas com maior poder antioxidante requerem maiores potenciais para oxidação das bases de DNA (ex. adenina, guanina). ${ }^{75}$ Os resultados para atividade antioxidante obtidos pelo método proposto para compostos fenólicos, tais como ácidos cafeico e rosmarínico, bem como para alguns extratos vegetais, apresentaram boa correlação com métodos coloriméticos tradicionais, como o método de DPPH. ${ }^{76}$

O método colorimétrico conhecido como FRAC (Ferric Reducing/Antioxidant Capacity $)^{77}$ e seu derivado eletroanalítico CRAC (Ceric Reducing/Antioxidant Capacity) podem ser considerados métodos indiretos para determinação do potencial antioxidante. O método CRAC emprega a cronoamperometria como técnica de detecção e utiliza uma solução ácida de sulfato de cério(IV) como oxidante. Este método se baseia no poder de redução das amostras sobre $\mathrm{Ce}^{+4}$ e os resultados obtidos apresentaram boa correlação com métodos tradicionais. ${ }^{78}$ Uma desvantagem do método reside no fato de que Ce (IV) é um forte agente oxidante, de modo que, em amostras mais complexas, se pode perder seletividade, porém por outro lado inúmeras vantagens podem ser citadas, dentre elas, a maior facilidade no pré-tratamento da amostra, a utilização de equipamentos mais baratos e maior simplicidade analítica, além do inerente poder oxidante do $\mathrm{Ce}^{4+}$ (potencial redox de $1,29 \mathrm{~V}$ versus $\mathrm{Ag} / \mathrm{AgCl}$ ) que reage praticamente com todos os antioxidantes conhecidos presentes na dieta humana.

\section{CONCLUSÕES}

Os testes in vitro têm se tornado importantes ferramentas que auxiliam na busca por substâncias bioativas, bem como na seleção de matéria-prima para estudo. Estes testes têm demonstrado a importância de dietas ricas em frutas e vegetais, comprovando a presença de substâncias antioxidantes, as quais auxiliam no combate aos radicais livres. Devido à crescente busca por substâncias bioativas que substituam os produtos sintéticos e diminuam os efeitos colaterais, um grande número de testes in vitro tem sido desenvolvido para avaliar a atividade antioxidante, porém muitos desses métodos não têm demonstrado correlação com a habilidade dos compostos em inibir a deterioração oxidativa in vivo. Isto se deve ao fato de que a atividade antioxidante depende não somente da reatividade química do antioxidante, mas também de fatores como localização física, interação com outros componentes e condições ambientais. Devido aos diversos tipos de radicais e aos diferentes alvos de oxidação, dificilmente haverá um único método capaz de representar de forma segura e precisa a real atividade antioxidante de um composto. Para uma avaliação correta desta atividade em alimentos e sistemas biológicos, modelos individuais devem ser desenvolvidos desde que representem as mesmas condições químicas, físicas e ambientais esperadas para o sistema em análise.

\section{AGRADECIMENTOS}

Ao CNPq e CAPES pelas bolsas de estudo e ao PRONEX(FAPESB/ CNPq) pelos auxílios financeiros.

\section{REFERÊNCIAS}

1. Larson, R. A.; Naturally Occcurring Antioxidants, Lewis Publishers: New York, 1997, p. 1.

2. Bae, G. U.; Seo, D. W.; Kwon, H. K.; Lee, H. Y.; Hong, S.; Lee, Z. W.; Ha, K. S.; Lee, H. W.; Han, J. W.; J. Biol. Chem. 1999, 274, 32596.

3. Shami, N. J. I. E.; Moreira, E. A. M.; Rev. Nutr. 2004, 17, 227.

4. Halliwell, B.; Gutteridge, J. M. C.; Cross, C. E.; J. Lab. Clin. Med. 1992, 119, 598.

5. Silva, F. A. M.; Borges, M. F. M.; Ferreira, M. A.; Quim. Nova 1999, 22, 94.

6. Kanner, J.; German, J. B.; Kinsella, J. E.; Crit. Rev. Food Sci. 1987, 25, 317.

7. Takemoto, E.; Teixeira-Filho, J.; Godoy, H. T.; Quim. Nova 2009, 32, 1189; Guinazi, M.; Milagres, R. C. R. M.; Pinheiro-Sant'Ana, H. M.; Chaves, J. B. P.; Quim. Nova 2009, 32, 2098.

8. Ramalho, V. C.; Jorge, N.; Quim. Nova 2006, 29, 755.

9. Sánchez-Moreno, C.; Food Sci. Tech. Int. 2002, 8, 121.

10. Frankel, E. D.; Finley, J. W.; J. Agric. Food Chem. 2008, 56, 4901.

11. Halliwell, B.; Aeschbach, R.; Loliger, J.; Arouma, O. I.; Food Chem. Toxicol. 1995a, 33, 601.

12. Halliwell, B.; Biochem. Pharmacol. 1995b, 49, 1341.

13. Niki, E.; Nutrition 2002, 18, 524.

14. Decker, E. A.; Warner, K.; Mark, P. R.; Shahid, F.; J. Agric. Food Chem. 2005, 53, 4303.

15. Halliwell, B.; The Lancet 2000c, 355, 1179.

16. Sánchez-Moreno, C.; Food Sci. Tech. Int. 2002, 8, 121.

17. Molyneux, P.; Songklanakarin J. Sci. Technol. 2004, 26, 211.

18. Chen, C.; Tang, H.; Sutcliffe, L. H.; Belton, P. S.; J. Agric. Food Chem. 2000, 48, 5710 .

19. Szabo, M. R.; Iditoiu, C.; Chambre, D.; Lupea, A. X.; Chem. Pap. 2007, 61, 214; Reynertson, K. A.; Wallace, A. M.; Adachi, S.; Gil, R. R.; Hui, Y.; Basile, M. J.; D’Armiento, J.; Weinstein, I. B.; Kennelly, E. J.; J. Nat. Prod. 2006, 69, 1228; Marxen, K.; Vanselow, K. H.; Lippemeier, S.; Hintze, R.; Ruser, A.; Hansen, U.; Sensors 2007, 7, 2080; Barreiros, A. L. B. S.; David, J. M.; David, J. P.; Pharm. Biol. 2004, 42, 36; David, J. P.; Brandão, H. N.; Meira, M.; David, J. M.; de Queiroz, L. P.; Giulietti, A. M.; Branco, A.; Agra, M. de F.; Fitoterapia 2007, 78, 215.

20. Brand-Williams, W.; Cuvelier, M. E.; Berset, C.; Lebensm.Wiss. Technol. 1995, 28, 25.

21. Sánchez-Moreno, C.; Larrauri, J. A.; Saura-Calixto, F.; J. Sci. Food Agric. 1998, 76, 270; Sánchez-Moreno, C.; Larrauri, J. A.; Food Sci. Technol. Int. 1998, 4, 391.

22. Sánchez-Moreno, C.; Larrauri, J. A.; Saura-Calixto, F.; J. Sci. Food Agric. 1999, 79, 1301.

23. Prior, R. L.; Wu, X.; Schaich, K.; J. Agric. Food Chem. 2005, 53, 4290.

24. Larson, R. A. Em ref. 1, p. 25.

25. Marco, G. J.; J. Am. Oil Soc. 1968, 45, 594.

26. Miller, H. E.; J. Am. Oil Soc. 1971, 48, 91.

27. Broinizi, P. R. B.; Andrade-Wartha, E. R. S. De; Silva, A. M. O.; Novoa, A. J. V.; Torres, R. P.; Azeredo, H. M. C.; Alves, R. E.; Mancini, J.; Ciênc. Tecnol. Aliment. 2007, 27, 902.

28. Barreiros, A. L. B. S.; David, J. P.; de Queiroz, L. P.; David, J. M.; Phytochemistry 2000, 55, 805; David, J. P.; Santos, E. O. Dos; Miranda, M. S.; Barreiros, A. L. B. S.; Santos, I. D. Dos; David, J. M.; Rev. Bras. Farmacogn. 2002, 12, 5; Vale, A. E. do; David, J. M.; Brandão, H. N.; David, J. P.; Z. Naturforsch., C: J. Biosci. 2005, 60, 45. 
29. Bandyopadhyay, M.; Raychaudhuri, U.; Chakraborty, R.; Food. Sci. Technol.-LEB 2008, 41, 816.

30. Hassimotto, N. M. A.; Genovese, M. I.; Lajolo, F. M.; J. Agric. Food Chem. 2005, 53, 2928.

31. Asolini, F. C.; Tedesco, A. M.; Carpes, S. T.; Ferraz, C.; Alencar, S. M. de; J. Food Technol. 2006, 9, 209; Silva, D. C. F.; Nascimento, M. A.; Moreira, A. V. B.; J. Braz. Soc. Food Nutr. 2007, 32, 41; Mandob, D. E.; Agbor, G.; Fomekong, G. I. D.; Ngondi, J. L.; Oben, J. E.; Pharmacologyonline 2008, 2, 769 .

32. Duarte-Almeida, J. M.; Santos, R. J.; Genovese, M. I.; Lajolo, F. M.; Ciênc. Tecnol. Aliment. 2006, 26, 446.

33. von Gadew, A.; Joubert, E.; Hansmann, C. F.; J. Agric. Food Chem. 1997, 45, 632

34. Rhys-Williams, A. T.; An introduction to fluorescence in biological analysis, Perkin-Elmer Ltd.: USA, 2000, p. 5.

35. Oliveira, A. C. de; Valentim, I. B.; Goulart, M. O. F.; Silva, C. A.; Bechara, E. J. H.; Trevisan, M. T. S.; Quim. Nova 2009, 32, 689.

36. Aruoma, O. I.; Halliwell, B.; Hoey, B. M.; Butler, J.; Free Radical Biol. Med. 1989, 6, 593.

37. Barreiros, A. L. B. S.; David, J. M.; David, J. P.; Quim. Nova 2006, 29, 113.

38. Corbett, J. T.; J. Biochem. Bioph. Meth. 1989, 18, 297.

39. Szatrowski, T. P.; Nathan, C. F.; Cancer Res. 1991, 51, 794.

40. Gomes, A. J.; Lunardi, C. N.; Gonzalez, S.; Tedesco, A. C.; Braz. Med. Biol. Res. 2001, 34, 1487.

41. Glazer, A. N.; FASEB J. 1988, 2, 2487.

42. Cao, G.; Verdon, C. P.; Wu, A. H.; Wang, H.; Prior, R. L.; Clin. Chem. 1995, 41, 1738; Cao, G.; Alessio, H. M.; Cutler, R. G.; Free Radical Biol. Med. 1993, 14, 303.

43. Atanasiu, R. L.; Stea, D.; Mateescu, M. A.; Vergely, C.; Dalloz, F.; Briot, F.; Maupoil, V.; Nadeau, R.; Rochette, L.; Mol. Cell. Biochem. 1998, 189, 127.

44. Cao, G.; Sofi, E.; Prior, R. L.; Free Radical Biol. Med. 1997, $22,749$.

45. Cao, G.; Prior, R. L.; Methods Enzymol. 1999, 299, 50.

46. Kamo, T.; Sato, K.; Sem, K.; Shibata, H.; Hirota, M.; J. Nat. Prod. 2004, 67, 958.

47. Dew, T. P.; Day, A. J.; Morgan, M. R. A.; J. Agric. Food Chem. 2005, 53, 6510.

48. Rao, R. J.; Tiwari, A. K.; Kumar, U. S.; Reddy, S. V.; Alib, A. Z.; Raoa, J. M.; Bioorg. Med. Chem. Lett. 2003, 13, 2777.

49. Robak, J.; Gryglewsk, R. J.; Biochem. Pharmacol. 1988, 37, 837; Yamaguchi, F.; Ariga, T.; Yoshimura, Y.; Nakazawa, H.; J. Agric. Food Chem. 2000, 48, 180.

50. da Silva, J. M. R.; Darmon, N.; Fernandez, Y.; Mitjavilat, S.; J. Agric. Food Chem. 1991, 39, 1549.

51. Gaulejac, N. S. De; Glories, Y.; Vivas, N.; Food Res. Int. 1999, 32, 327.

52. Wang, S. Y.; Jiao, H.; J. Agric. Food Chem. 2000, 48, 5677.

53. Cimanga, K.; Ying, L.; De Bruyne, T.; Apers S.; Cos, P.; Hermans, N.; Bakana, P.; Tona, L.; Kambu, K.; Kalenda, D. T.; Pieters, L.; Vanden Berghe, D.; Vlietinck, A. J.; J. Pharm. Pharmacol. 2001, 53, 757; Abdelwahed, A.; Bouhlel, I.; Skandrani, I.; Valenti, K.; Kadri, M.; Guiraud, P.; Steiman, R.; Mariotte, A. M.; Ghedira, K.; Laporte, F.; Dijoux-Franca, M. G.; Chekir-Ghedira, L.; Chem.-Biol. Interact. 2007, 165, 1.

54. Cos, P.; Ynig, L.; Calomme, M.; Hu, J. P.; Cimanga, K.; van Poel, B.; Pieters, L.; Vlietinck, A. J.; Vanden Berghe, D.; J. Nat. Prod. 1998, 61, 71.
55. Filho, D. W.; Silva, E. D. Da; Boveris, A. Em Plantas Medicinais sob a Ótica da Moderna Química Medicinal, Ed. Argos: Chapecó, 2001, p. 327.

56. Ramallo, I. A.; Zacchino, S. A.; Furlan, R. L. E.; Phytochem. Anal. 2007, $17,15$.

57. Sarma, A. D.; Sharma, R.; Phytochemistry 1999, 52, 1313.

58. Gutteridge, J. M. C.; Halliwell, B.; Biochem J. 1988, 253, 932.

59. Halliwell, B.; Gutteridge, J. M. C.; Aruoma, O. E. I.; Anal. Biochem. 1987, 165, 215.

60. Aruoma, O. I.; Murcia, A.; Butler, J.; Halliwell, B.; J. Agric. Food Chem. 1993, 41, 1880.

61. Martínez-Tomé, M.; García-Carmona, F.; Murcia, M. A.; J. Sci. Food Agric. 2001, 81, 1019.

62. Hagerman, A. E.; Riedl, K. M.; Jones, G. A.; Sovik, K. N.; Ritchard, N. T.; Hartzfeld, P. W.; Richel, T. L.; J. Agric. Food Chem. 1998, 46, 1887.

63. Aruoma, O. I.; Methods Enzymol. 1994, 233, 57; Roussis, I. G.; Lambropoulos, I.; Soulti, K.; Food Technol. Biotechnol. 2005, 43, 351.

64. Oboh. G.; Helen, T.; J. Med. Food 2009, 12, 77.

65. Omodeo-Sale, F.; Gramigna, D.; Campaniello, R.; Neurochem. Res. 1997, 22, 577.

66. Kaptanoglu, E.; Solaroglu, I.; Akbiyik, F.; Demirpençe, E.; Ergungor, M. F.; Turk. Neurosurgery 2003, 13, 9 .

67. Fernández, J.; Pérez-Álvarez, J. A.; Fernández-López, J. A.; Food Chem. 1997, 59, 345.

68. Miyamoto, S.; Martinez, G. R.; Rettori, D.; Augusto, O.; Medeiros, M. H. G.; Mascio, P. D.; Proc. Natl. Acad. Sci. U. S. A. 2006, 103, 293.

69. Wasil, M.; Halliwell, B.; Hutchison, D. C. S.; Baum, H.; Biochem. J. 1987, 243, 219.

70. Zare, H. R.; Namazian, M.; Nasirizade, N.; J. Electroanal. Chem. 2005, 584, 77; Janeiro, P.; Brett, A. M. O.; Anal. Chim. Acta 2004, 518, 109; Kosina, P.; Kren, V.; Gebhardt, R.; Grambal, F.; Ulrichova, J.; Walterova, D.; Phytoter. Res. 2002, 16, S33.

71. Brett, A. M. O.; Ghica, M. E.; Electroanalysis 2003, 15, 1745; Roginsky, V.; Barsukova, T.; Hsu, C. F.; Kilmartin, P. A.; J. Agric. Food Chem. 2003, 51, 5798.

72. Chevion, S.; Roberts, M. A.; Chevion, M.; Free Radical Biol. Med. 2000, 28, 860; Hotta, H.; Nagano, S.; Ueda, M.; Tsujino, Y.; Koyama, J.; Osakai, T.; Biochim. Biophys. Acta 2002, 1572, 123.

73. Hootta, H.; Ueda, M.; Nagano, S.; Tsujino, Y.; Koyama, J.; Osakai, T.; Anal. Biochem. 2002, 303, 66.

74. Papanikos, A.; Eklund, J.; Jackson, W. R.; Kenche, V. B.; Campi, E. M.; Robertson, A. D.; Jarrott, B.; Beart, P. M.; Munro, F. E.; Callawaty, J. K.; Aust. J. Chem. 2002, 55, 205.

75. Brett, A. M. O.; Diculescu, V. C.; Bioelectrochemistry 2004, 64, 143; Zhu, Z.; Li, C.; Li, N. Q.; Microchem. J. 2002, 71, 5; Gil, E. S.; Serrano, S. H. P.; Ferreira, E. I.; Kubota, L. T.; J. Pharm. Biomed. Anal. 2002, 2, 579.

76. Labuda, J.; Buckova, M.; Heilerova, L.; Caniova-Ziakova, A.; Brandsteterova, E.; Mattusch, J.; Mattusch, J.; Wennrich, R.; Sensors 2002, 2, 1.

77. Benzie, I. F.; Strain, J. J.; Anal. Biochem. 1996, 239, 70.

78. Ferreira, R. Q.; Avaca, L. A.; Quim. Nova 2008, 31, 2169. 